\title{
Spray-Dried Alginate Microparticles for Potential Intranasal Delivery of Ropinirole Hydrochloride: Development, Characterization and Histopathological Evaluation
}

Nozad Hussein, Huner Omer, Ava Ismael, Mohamed Albed Alhnan, Abdelbary Elhissi \& Waqar Ahmed

To cite this article: Nozad Hussein, Huner Omer, Ava Ismael, Mohamed Albed Alhnan, Abdelbary Elhissi \& Waqar Ahmed (2019): Spray-Dried Alginate Microparticles for Potential Intranasal Delivery of Ropinirole Hydrochloride: Development, Characterization and Histopathological Evaluation, Pharmaceutical Development and Technology, DOI: 10.1080/10837450.2019.1567762

To link to this article: https://doi.org/10.1080/10837450.2019.1567762

Accepted author version posted online: 10 Jan 2019.

Submit your article to this journal ¿

山 Article views: 18

View Crossmark data \lceil 


\section{Spray-Dried Alginate Microparticles for Potential Intranasal Delivery of Ropinirole Hydrochloride: Development, Characterization and Histopathological Evaluation}

\footnotetext{
${ }^{1,2}$ Nozad Hussein, ${ }^{1,2}$ Huner Omer, ${ }^{2}$ Ava Ismael, ${ }^{1,3}$ Mohamed Albed Alhnan, ${ }^{4,5}$ Abdelbary Elhissi, ${ }^{6}$ Waqar Ahmed
}

${ }^{1}$ School of Pharmacy and Biomedical Sciences, University of Central Lancashire, Preston, United Kingdom

${ }^{2}$ College of Pharmacy, Hawler Medical University, Erbil, Iraq

${ }^{3}$ Institute of Pharmaceutical Science, King's College London, Waterloo, UK

${ }^{4}$ Office of Vice President for Research and Graduate Studies, Qatar University, Doha, Qatar

${ }^{5}$ College of Pharmacy, Qatar University, Doha, Qatar

${ }^{6}$ School of Mathematics and Physics, College of Science, University of Lincoln, UK

*Corresponding author:

Professor Waqar Ahmed

Professor of Nanoscience and Deputy Head of School

School of Mathematics and Physics, College of Science

University of Lincoln, Lincoln LN6 7TS

United Kingdom

E:wahmed@lincoln.ac.uk

T: 01522835761 


\title{
Spray-Dried Alginate Microparticles for Potential Intranasal Delivery of Ropinirole Hydrochloride: Development, Characterization and Histopathological Evaluation
}

\begin{abstract}
Ropinirole hydrochloride $(\mathrm{RH})$ is an anti-Parkinson drug with relativity low oral bioavailability owing to its extensive hepatic first pass metabolism. Spray-dried mucoadhesive alginate microspheres of RH were developed and characterized followed by histopathological evaluation using nasal tissue isolated from sheep. Spherical microparticles having high product yield (around 70\%) were obtained when the inlet temperature of spray drying was $140^{\circ} \mathrm{C}$. Fourier Transform Infrared (FTIR) studies revealed the compatibility of the drug with the polymer, and scanning electron microscopy (SEM) showed that drug-loaded microparticles were spherical, and the apparent surface roughness was inversely related to the ratio of polymer to drug. Furthermore, size of the spray-dried particles were in the range of $2.5-4.37 \mu \mathrm{m}$, depending on formulation. All formulations had high drug encapsulation efficiencies $(101-106 \%)$. Drug loaded into the polymeric particles was in the amorphous state and drug molecules were molecularly dispersed in the polymeric matrix of the microparticles which were revealed by X-ray diffraction and differential scanning calorimetry (DSC), respectively. The in vitro drug release was influenced by polymer concentration. Histopathological study demonstrated that RH-loaded sodium alginate microparticles was safe to nasal epithelium. In conclusion, spray drying of RH using sodium alginate polymer has produced microparticles of suitable characteristics for potential intranasal administration.
\end{abstract}

Keywords: CNS, Microspheres, Nose, Ropinirole hydrochloride, Sodium alginate, Spray drying 


\section{Introduction}

Microparticles are established drug delivery systems designed by incorporating drugs into polymeric excipients in order to modulate the drug release and enhance absorption by exploiting the high surface area to volume ratio of the particles (Gavini et al., 2006; Nidhi et al., 2016). Formulation of drug in powdered microparticulate systems may enhance chemical stability of drug and excipients. Powder formulations can be designed without inclusion of preservatives and can be used for delivery of relatively large molecules (e.g. peptides) and conventional small drug molecules (Chaturvedi et al., 2011). Furthermore, It has been previously reported that drug bioavailability can be improved when microparticles are given intranasally as powders compared to the corresponding liquid formulations (Ishikawa et al., 2001; Rassu et al., 2015; Salade et al., 2018).

Delivery of drugs via the nose can be used to treat local diseases within the nasal cavity such as rhinitis and nasal congestions, and for targeting the central nervous system (CNS) to treat diseases such as migraine (Chaturvedi et al., 2011). The nasal cavity can be exploited for drug delivery because of its large surface area $\left(150 \mathrm{~cm}^{2}\right)$ and high blood vascularity, offering enhanced drug absorption through the nasal epithelium. The nose, as a route of administration, is particularly suitable for drugs that undergo extensive first pass hepatic deactivation, because the drug is directly absorbed to the systemic circulation without passing through the portal vein to the liver (Chaturvedi et al., 2011). Furthermore, the neuronal connection in the nose has attracted many researchers to explore the potential of this organ for delivering drugs to the central nervous system (Wen 2011; Kumar et al., 2013), which may minimize the potential of systemic adverse effects (Kumar et al., 2013). 
Drugs administered intranasally in the form of solutions are usually cleared rapidly (within around $15 \mathrm{~min}$ ) by mucociliary clearance mechanism from the nasal cavity towards the nasopharyngeal region (Mao et al., 2004). Mucoadhesive agents, also referred to as bioadhesive agents, have been investigated with the aim of enhancing drug absorption across the epithelial cells of the nose (Jiang et al., 2010; Salade et al., 2018). Incorporation of drugs into mucoadhesive delivery systems is a highly promising strategy for enhancing drug absorption through the nasal epithelium. This is attributed to the ability of mucoadhesive polymers to interfere with the movement of the ciliary structures of the nasal membranes, resulting in prolonged contact of the drug with the mucosal surfaces and enhanced drug absorption (Illum 2003; Lee et al., 2017).

Mucoadhesive polymer excipients are natural, synthetic or semi synthetic that can prolong the time of contact between the incorporated drug and the nasal epithelium for up to $5 \mathrm{~h}$, depending on the characteristics of the polymer. This can help with enhancing the absorption of drugs that are known to have poor bioavailability (Yeom et al., 2017). Patil and co-workers (2012) have reported enhanced nasal absorption and bioavailability of carvedilol upon drug incorporation into sodium alginate microspheres.

Sodium alginate is a promising natural polyanionic polymer for controlled drug release, owing to its low price, minimal toxicity and high biodegradability (Farid et al., 2012). The mucoadhesiveness of polymer has been reported to be directly proportional to its molecular weight and to the presence of polar groups in its structure (Kharenko et al., 2009). Mucoadhesive properties of sodium alginate are attributed to hydrogen bond formation resulting from carboxyl-hydroxyl interactions with mucin (Patil et al., 2012; Farid et al., 2012). Alginate microparticles have demonstrated ability to accommodate a wide variety of active constituents including macromolecules (e.g. peptides and proteins) (Coppi et al., 2002), 
small molecules (e.g. ranitidine) (Szekalska et al., 2015) and lipopolysaccharides (Jain et al., 2015).

Ropinirole hydrochloride ( $\mathrm{RH})$ is a non-ergoline anti-Parkinson drug. $\mathrm{RH}$ is a selective agonist of $\mathrm{D}_{2}$ dopamine-like receptors (DrugBank, 2013), and is established for management of Parkinson's disease, either alone or in combination with other drugs, in order to minimize the on-off fluctuations in response to levodopa. The drug has a relatively low oral bioavailability (around 50\%), owing to its inactivation by the liver (DrugBank, 2013).

In this work, we employed spray drying to prepare spherically shaped microparticles (i.e. microspheres) for incorporation of RH using sodium alginate as a delivery system. The effect of spray drying inlet air temperature on the microparticulate powder characteristics including particle shape, powder yield, and particle size and size distribution were all investigated. Spray drying parameters were optimized and used to develop RH-sodium alginate microspheres, and extensive characterization studies were conducted to explore the potential of these formulations for intranasal administration. Furthermore, safety of RH-alginate microparticles was evaluated through a histopathology study using an isolated nasal sheep mucosa.

\section{Materials and methods}

\subsection{Materials}

Ropinirole hydrochloride (RH) was purchased from Shanghai Yancui, Republic of China. Low viscosity sodium alginate, sodium hydroxide, sodium phosphate monobasic, haematoxylin, eosin and deoxycholate hydrate were supplied by Sigma Aldrich, UK. 
Absolute ethanol, acetonitrile, water and 1-butanol were all of high performance liquid chromatography (HPLC)-grade and were supplied by Fisher Scientific Ltd., UK.

\subsection{Methods}

\subsubsection{Optimization of sodium alginate microsphere $(0.5 \%)$ formulations}

Formulation and spray drying parameters were optimized for preparing RH-sodium alginate microspheres. Sodium alginate $(500 \mathrm{mg})$ was dissolved in HPLC-grade water $(100 \mathrm{~mL})$ with aid of magnetic stirring. The resulting solution was divided into three equal portions, each was spray-dried separately by employing the Büchi-290 Mini Spray-dryer (Büchi Laboratories, Switzerland) and using three different inlet temperatures; $120^{\circ} \mathrm{C}, 140^{\circ} \mathrm{C}$, and $160^{\circ} \mathrm{C}$ while other conditions were fixed (aspirator rate was $100 \%$, spray gas flow was $357 \mathrm{~L} / \mathrm{hr}$ and feed pump rate was set at $17 \mathrm{ml} / \mathrm{min}$ ), which gave outlet temperatures in the ranges of $56-58^{\circ} \mathrm{C}, 64-71^{\circ} \mathrm{C}$, and $72-81^{\circ} \mathrm{C}$, respectively. The resultant powdered microspheres were characterized in terms of production yield, particle size, particle size distribution and microscopic morphology.

\subsubsection{Production yield determination}

The production yield was calculated as the percentage weight of the yielded spray-dried powder over the total amount of RH and alginate originally used prior to spray-drying (Omer et al., 2018), using the following equation:

$$
\text { Yield }(\%)=\left(\frac{\mathrm{W} 1}{\mathrm{~W} 2}\right) * 100
$$

Where W1 is the weight of spray-dried microparticles and W2 is the initial dry weight of the starting material before spray drying. 


\subsubsection{Size analysis of microparticles}

Size measurements were conducted by weighing $5 \mathrm{mg}$ of the alginate microparticles generated by spray drying, followed by dispersion in 1-butanol $(3 \mathrm{~mL})$ and sonication for $15 \mathrm{~s}$ to deaggregate the particles. The resultant particulate dispersion was further diluted with 1butanol and size was analyzed using laser diffraction (Malvern Mastersizer 2000, Malvern Instruments Ltd., UK). The size was expressed as the volume median diameter (VMD; D0.5; $50 \%$ undersize), and size distribution (i.e. polydispersity) was expressed as Span (a term introduced by Malvern Instruments Ltd, UK, to express size distribution of particles):

$$
\text { Span }=\frac{(\mathrm{D} 0.9-\mathrm{D} 0.1)}{\mathrm{D} 0.5}
$$

where D0.5, D0.9 and D0.1 are 50\% undersize (VMD), 90\% undersize and 10\% undersize, respectively (Gavini et al. 2006; Khan et al., 2015).

\subsubsection{Scanning electron microscopy (SEM) of spray-dried microparticles}

Microparticles were mounted onto a carbon pad (Agar Scientific, UK), and coated with a thin film of gold using the sputter coater of the microscope (Bio-Rad, England). The morphology of the particles was investigated under vacuum using the Quanta 200 scanning electronic microscope.

\subsubsection{Compatibility studies between RH and the polymer}

The compatibility between the drug and the polymer was studied using spray-dried $\mathrm{RH}$ loaded alginate microparticles $(1: 1 \mathrm{w} / \mathrm{w})$. Fourier Transform Infrared (FTIR) spectroscopy and thin layer chromatography (TLC) were employed to detect possible interactions or bond formation between RH and sodium alginate. The IR spectrum of the formulations and physical mixture of the drug and the polymer were then analyzed in comparison with the spectrum of RH raw material. The solution of RH raw material, physical mixture, and RHloaded microparticles $(1: 1 \mathrm{w} / \mathrm{w})$ equivalent to $400 \mu \mathrm{g} / \mathrm{mL}$ of the drug were prepared and 
studied separately using TLC and then dried using a lab drier. The TLC chamber was filled with the mobile phase (methanol and acetonitrile; 80:20 v/v), and a drop of glacial acetic acid was added to prevent possible tailing of the spot. The chamber was allowed to saturate with the mobile phase at room temperature for $20 \mathrm{~min}$ prior to starting the TLC experiments. The spotted TLC had been placed into the chamber and left for enough time before it was dried at room temperature. The spots of RH were then detected using UV (Patel and Chaudhari, 2012).

\subsubsection{Preparation of RH-loaded sodium alginate microparticles}

Using a range of polymer to drug ratios (Table 1), five formulations were prepared using low viscosity sodium alginate (melting point $>300^{\circ} \mathrm{C}$ ) and RH (melting point $235-243^{\circ} \mathrm{C}$ ). Spraydried $\mathrm{RH}$-free microparticles $(0.5 \% \mathrm{w} / \mathrm{v}$; formulation A1) were prepared for comparison using the same spray drying parameters. The feed solutions were prepared by dissolving the drug and the polymer in $100 \mathrm{~mL}$ of HPLC-grade water, followed by viscosity determination of the resultant solution using an automated microviscometer (described in the subsequent section) before commencing spray drying. The feed solution $(200 \mathrm{~mL})$ was spray-dried through the 0.7 $\mathrm{mm}$ nozzle, using an inlet temperature of $140^{\circ} \mathrm{C}$, outlet temperature of $64-71^{\circ} \mathrm{C}$, aspiration rate of $100 \%$, gas flow rate at $357 \mathrm{~L} / \mathrm{h}$ and pump ratio of $17 \%(5-6 \mathrm{~mL} / \mathrm{min})$.

\subsubsection{Measurement of feed solution viscosity and density}

Prior to conducting spray drying, solution viscosity and density were measured at $20^{\circ} \mathrm{C}$ using the Anton Paar microviscometer (AMVn automated model, Anton Paar, Austria) and DMA 35N density meter (Anton Paar, Austria), respectively. 


\subsubsection{Encapsulation efficiency of RH in alginate microparticles}

The encapsulation efficiency of the drug in the polymeric microparticles was investigated. Drug-loaded microparticles $(4 \mathrm{mg})$ were dispersed into phosphate buffer solution $(30 \mathrm{~mL}$; $\mathrm{pH}$ 6.5) and left for $5 \mathrm{~h}$ before vortex mixing for $1 \mathrm{~min}$ to extract the entrapped drug. The solution was then filtered through micro filters $(0.22 \mu \mathrm{m})$ and analysed using HPLC (Agilent 1200, Agilent technology Ltd., USA) to determine the drug encapsulation efficiency (EE) and drug loading (DL) in the microparticles using equations 3 and 4, respectively.

$$
\begin{aligned}
& \mathrm{EE}(\%)=\left(\frac{\text { Amount of encapsulated drug }}{\text { Theoritical drug content }}\right) \times 100 \\
& \mathrm{DL}(\%)=\left(\frac{\text { Weight of drug loaded in microspheres }}{\text { Total Weight of microspheres }}\right) \times 100
\end{aligned}
$$

\subsubsection{Zeta potential analysis}

Microparticles were dispersed in phosphate buffer solution ( $\mathrm{pH}$ 6.5), then corresponding zeta potential measurements were conducted by measuring the electrophoretic mobility through using the Malvern Zetasizer instrument with the relevant software option (Malvern Instruments Ltd. UK).

\subsubsection{X-ray diffraction studies}

RH, sodium alginate and RH-loaded microparticles were studied using X-ray diffractometry (Equinox 2000 Inel, France). The powder samples were spread onto the metal sample holders of the instrument, and glass slides were used to smoothen the powder surfaces. The diffraction intensity was recorded at 2-theta and the run duration was $20 \mathrm{~min}$. The current and voltage generator were set at $28 \mathrm{~mA}$ and $32 \mathrm{KV}$, respectively.

\subsubsection{Differential scanning calorimetry (DSC)}

Thermal behaviour of the drug formulations was investigated using differential scanning calorimetry (DSC823e, Mettler Toledo, UK). In this study, a physical mixture of the drug 
with the polymer was compared to the drug-loaded microparticles and polymer-free drug samples. Before running of samples, DSC was calibrated with indium and zinc oxide. Approx. $3.5-4 \mathrm{mg}$ of each sample was placed into the aluminium pan $(40 \mu \mathrm{L})$ which was then sealed and heated at $10^{\circ} \mathrm{C} / \mathrm{min}$ from 35 to $300^{\circ} \mathrm{C}$.

\subsubsection{Thermogravimetric analysis (TGA)}

Weight loss as a result of heating was studied using thermogravimetric analysis (TGA) by employing the SDTA851e thermogravimetric analyser (Mettler Toledo, UK) under a purge of nitrogen gas. Approx. $4.9 \mathrm{mg}$ of powder was placed into the aluminium pan (40 $\mu \mathrm{L})$ and sealed using a sealing crucible. The cover of the pan was pierced with a pin to allow evaporation of moisture during heating. The sample was then placed onto the highly sensitive balance $\left(0.01 \mathrm{mg}\right.$ accuracy) and the heating rate applied was $10^{\circ} \mathrm{C} / \mathrm{min}$ between 20 and $300^{\circ} \mathrm{C}$. The change in mass was determined and the percentage weight loss was calculated for each sample.

\subsubsection{In vitro drug release}

Microparticle powder containing $2 \mathrm{mg}$ of $\mathrm{RH}$ was dispersed into phosphate buffer solution (70 mL; pH 6.5) within a glass container. The temperature was maintained at $37^{\circ} \mathrm{C} \pm 0.20$, and shaking was performed in a water bath $(100 \mathrm{rpm})$. Samples were taken at time intervals $(0.5,1,2,5,10,20,30,60$ and $90 \mathrm{~min})$ and replaced with the same volume of formulationfree dissolution medium in order to keep a sink condition. The rate of drug release was analysed using HPLC (Huh et al., 2010).

\subsubsection{Histopathological study}

The histopathology study was conducted on the nasal tissue of an animal that had already been sacrificed. Ethical clearance application was submitted to the College of Pharmacy at 
Hawler Medical University. Following approval at the College level, the application was forwarded to the research committee of the university, which subsequently approved the planned experiments within the scope described in this section. Accordingly, fresh nasal mucosa was isolated immediately after sacrificing a healthy eight month Makui sheep, according to the procedure previously described by Seju et al., (2011). The nasal mucosa was sectioned into four pieces; each was treated for $2 \mathrm{~h}$ with formulation dispersion containing 2 $\mathrm{mg} / \mathrm{mL}$ of RH-loaded into alginate microspheres (90:10 polymer to drug ratio). Drug in phosphate buffer solution ( $2 \mathrm{mg} / \mathrm{mL}$; $\mathrm{pH}$ 6.5) was used for comparison in parallel experiments. In our studies, phosphate buffer ( $\mathrm{pH}$ 6.5) and sodium deoxycholate $(1 \% \mathrm{w} / \mathrm{v})$ solutions were used as negative control and positive control, respectively. Subsequently, tissue samples were washed with $\mathrm{NaCl}(0.9 \%)$ and fixed in $10 \%$ buffered formalin and embedded in paraffin wax for $4 \mathrm{~h}$. Paraffin sections 7 - $5 \mathrm{~mm}$ were placed on glass slides and stained with haematoxylin and eosin, followed by light microscopy examination to investigate whether any damage during incubation had happen in the sample tissue. Examination included all essential components of the nasal epithelium cells such as goblet cells, ciliated cells, mucosal and sub-mucosal layers, and sero-mucinous glands. The samples were studied for possible epithelial necrosis, and sloughing of the epithelial and inflammatory cells.

\subsubsection{Statistical analysis}

All experiments were conducted three times. One-way Analysis of Variance (ANOVA) and student's t-tests were employed, to compare more than two groups of data and two groups of results, respectively. The measured values were calculated as mean \pm standard deviations and when $p$ was less than or equal to 0.05 , the difference between the samples compared was regarded to be statistically significant. 


\section{Results and discussion}

\subsection{Optimization of sodium alginate microparticles}

\section{(i) Production yield}

The production yield (\%) of alginate microparticles at different inlet temperatures was 58.87 $\% \pm 2.95$ (inlet temp. $120^{\circ} \mathrm{C}$ ), $68.13 \% \pm 0.37$ (inlet temp. $140^{\circ} \mathrm{C}$ ), and $70.27 \% \pm 1.26$ (inlet temp. $160^{\circ} \mathrm{C}$ ). In the study of the effect of inlet temperature on the powder production yield, all other spray-drying parameters were kept constant. The production yield (\%) of alginate microparticles decreased $(\mathrm{p}<0.05)$ from $70.27 \pm 1.26$ to $58.87 \pm 2.95$ as the inlet temperature was decreased from $160^{\circ} \mathrm{C}$ to $120^{\circ} \mathrm{C}$, which caused a decrease in the outlet temperature from $77.2 \pm 2.7^{\circ} \mathrm{C}$ to $59.2 \pm 2^{\circ} \mathrm{C}$, respectively. This might be ascribed to the lower heat energy available in the drying chamber, which is required to dry the atomized droplets quickly before they leave the spray drying without being appropriately dried. Rathananand and co-workers (2007) have reported that increasing the inlet air temperature during spray drying resulted in yield promotion, agreeing with our findings in this study.

\section{(ii) Particle size and size distribution of the alginate microparticles}

The volume median diameter (VMD; 50\% undersize) and size distribution (expressed as 'Span') of sodium alginate microparticles prepared at different inlet temperatures were respectively $2.35 \pm 0.12 \mu \mathrm{m}$ and $2.11 \pm 0.53$ (Inlet temperature $120^{\circ} \mathrm{C}$ ), $2.58 \pm 0.06 \mu \mathrm{m}$ and $2.71 \pm 0.02$ (Inlet temperature $140^{\circ} \mathrm{C}$ ), and $2.5 \pm 0.10 \mu \mathrm{m}$ and $1.94 \pm 0.41$ (Inlet temperature $\left.160^{\circ} \mathrm{C}\right)$.

The size of microparticles had a narrow range (between $2.35 \pm 0.10$ and $2.58 \pm 0.06 \mu \mathrm{m}$ ) and the Span was $2.11 \pm 0.53$ and $2.71 \pm 0.02$ for microparticles prepared at $120^{\circ} \mathrm{C}$ and $140^{\circ} \mathrm{C}$, respectively. Thus, no statistical difference in size or size distribution as a result of changing the inlet air temperature (comparing $160^{\circ} \mathrm{C}$ to $120^{\circ} \mathrm{C}$ ) was observed $(\mathrm{p}>0.05)$. However, a 
propensity of particle size to decrease was observed when relatively low inlet temperature was used (i.e. $120^{\circ} \mathrm{C}$ ). These results are in disagreement with the findings previously reported by Tee et al., (2012) who prepared spray-dried Sirih coated by maltodextrin using spray drying. This suggests that different excipients, as a result of having different physicochemical characteristics, may have different drying behaviour during spray drying.

\section{(iii) Microparticle morphology studies using SEM}

Figure 1 shows SEM morphology characteristics of microparticles prepared using different inlet temperatures $\left(120,140\right.$ and $\left.160^{\circ} \mathrm{C}\right)$. SEM images demonstrated that many particles generated at $160^{\circ} \mathrm{C}$ inlet temperature were dimpled and perforated. By contrast, microparticles prepared using a lower inlet temperature (e.g. $120^{\circ} \mathrm{C}$ ) were spherical, and their surface had fissures/cracks. This can be attributed to the incomplete water evaporation from the atomized droplets at this low temperature (Figure 1c). Based on our experiments, inlet air temperature of $140^{\circ} \mathrm{C}$ was selected as it was found to minimize the propensity of spherical particles to become perforated during drying. Spherical microparticles are established to have higher flowability than their non-spherical counterparts. Thus, in this study, the inlet temperature of $140^{\circ} \mathrm{C}$ was used to prepare various $\mathrm{RH}-1$ oaded sodium alginate formulations.

\section{(iv) Compatibility studies}

Compatibility studies were conducted to detect possible interactions between RH and the polymer. Undesirable interactions between the drug and excipients can reduce formulation stability, and affect drug dissolution (Taylor and Zografi, 1997). Interactions between RH and sodium alginate were investigated using TLC and FTIR spectroscopy. When the drug (as a co-spray dried in the formulation), the physical mixture of the drug with the polymer and the polymer-free pure drug were compared, TLC studies showed that $\mathrm{R}_{\mathrm{f}}$ values of $\mathrm{RH}$ were 
similar $\left(\mathrm{R}_{\mathrm{f}}=0.55\right)$, and no extra spot was detected on the TLC plate. This observation indicates that no chemical interaction between the drug and the polymer has occurred.

In an attempt to validate the TLC compatibility findings, FTIR was used. Thus, FTIR spectrum of RH, sodium alginate, physical mixture of RH and sodium alginate and spraydried microparticle formulations $(50: 50 \mathrm{w} / \mathrm{w})$ were compared (Figure 2). Sharp peaks of RH were found at $1241.19,1455.36,1702.18$ and $3068.95 \mathrm{~cm}^{-1}$ for $\mathrm{C}-\mathrm{N}, \mathrm{C}=\mathrm{C}$ stretching, $\mathrm{C}=\mathrm{O}$ stretching and $\mathrm{N}-\mathrm{H}$ stretching functional groups respectively, whilst the IR spectrum of sodium alginate showed peaks at $3273.05,1595.091408 .25$ and $1026.88 \mathrm{~cm}^{-1}$ for $\mathrm{O}-\mathrm{H}$ stretching, $\mathrm{C}=\mathrm{O}$ stretching, $\mathrm{COO}-$ and $\mathrm{C}-\mathrm{O}-\mathrm{C}$ stretching respectively. When $\mathrm{IR}$ spectrum of pure RH was compared to the IR spectrum of physical mixture and spray dried RH loaded alginate microspheres, no remarkable band-shifts of wave number were observed. Thus, FTIR confirmed no merging of peaks of the drug with the polymer has occurred, indicating no chemical interaction between the components.

\subsection{Product yield and Size of microparticles}

Earlier, it was shown that inlet temperature of the spray drier significantly affected the yield. However, when the inlet temperature was fixed at $140^{\circ} \mathrm{C}$, aspiration rate at $100 \%$, gas flow rate at $357 \mathrm{~L} / \mathrm{h}$ and pump ratio at $17 \%(5-6 \mathrm{~mL} / \mathrm{min})$, no effect of formulation was found on product yield, being around $70 \%$ for all polymer to drug ratios (Table 2). Particle size (i.e. VMD) of RH-sodium alginate microspheres was smaller for formulation A2 compared to formulation A5 (Table 2). The increase in drug to polymer ratio resulted in an increase in the measured size of microparticles $(\mathrm{p}<0.05)$. Generally, particle size of the spray-dried particles is dependent on the characteristics of droplets atomized into the spray-drying chamber. In previous spray drying studies, droplet size has been reported to increase by increasing solution viscosity and feed rate, and to decrease by increasing gas flow rate (Chegini and 
Taheri, 2013). Hence, it is expected that size and size distribution of the microparticles produced can be engineered by manipulating the properties of the feed solution.

Size distribution was affected by formulation $(\mathrm{p}<0.05)$, so that Span values were dependent on formulation. In our experiments, changes in Span values between formulations are possibly caused by changing solution viscosity (Table 2). The significant decrease in feed solution viscosity $(\mathrm{p}<0.05)$ might be attributed to the decrease in the intermolecular entanglement, promoting the freedom of individual polymer chains movement in the solution (Graessley 1974). Thus, the decrease in polymer concentration (i.e. decrease in viscosity of feed solution) has produced larger particles with broader size distribution during atomization (Table 2). Interestingly, particle size and Span of RH as a raw material, without spray drying, were $59.72 \pm 3.07 \mu \mathrm{m}$ and $1.63 \pm 0.14$ respectively (findings not shown in the tables). However, following spray drying, the size and Span became 23.62 $\pm 4.66 \mu \mathrm{m}$ and $1.84 \pm 0.48$, respectively (findings not shown in the tables).

\subsection{Drug loading and encapsulation efficiency}

Figure 3 shows drug loading and encapsulation efficiency in the polymeric microparticles. Microsphere formulations had high encapsulation efficiencies (EE) (e.g. 101.55\% \pm 3.18 for A 3 and $106.99 \% \pm 1.77$ for A4 formulations). This might be due to the rapid evaporation of solvent from the droplets in the drying chamber, resulting in enhanced drug entrapment upon solidification of the excipient (Rathananand et al., 2007). These results are in agreement with those obtained by Alhalaweh and co-workers (2009) who reported entrapment efficiency values in the range of $93-105 \%$ for zolmitriptan loaded into chitosan microspheres designed for intranasal administration. 


\subsection{Zeta potential of microparticles}

Zeta potential of particles represents a major influence on their bioadhesive properties and ability to interact with epithelial cells (Patil et al., 2012). Alginate is negatively charged due to the ionization of the carboxyl moiety, causing hydrogen bond formation or Vander Waals interactions with mucin or sialic acid of the epithelial tissue (Patil et al., 2012). Zeta potential values of the formulations used in this study are presented in Table 2, clearly demonstrating higher negative charge intensity for formulations with higher alginate content. Clogston and Patri (2011) have reported that particles are likely to be stable when zeta potential values are higher than $25 \mathrm{mV}$, regardless of the charge type (i.e. negative or positive). Our findings demonstrated that the negative zeta potential values of the alginate microparticles decreased significantly $(\mathrm{p}<0.05)$ when the concentration of the polymer was decreased from A1 to A5 formulation (Table 2), possibly due to the decrease in the overall negative charge in the formulation when lower polymer proportions were used.

\subsection{Surface morphology of microparticles}

Figure 4 shows scanning electron microscopy images of RH powder before and after spray drying. RH particles became spherical upon spray drying in polymeric formulation (Figure 5) compared to spray-dried RH alone (î.e. without using the alginate polymer) (Figure 4).

The decrease in polymer to drug ratio decreased the proportion of perforated particles, which was evident in formulation A3 (Figure 5c). Further decrease in polymer to drug ratio made the particles spherically shaped and apparently increased surface roughness of the particles. For intranasal administered powders, optimization of particle size and morphology is needed to minimize the risk of nasal mucosa irritation, and to improve powder flowability and nasal deposition (Behl et al., 1998). The absence of irregular shape in the SEM images (Figure 5) indicates efficient encapsulation of $\mathrm{RH}$ in the microparticles. The success of spray drying to 
manufacture spherical microparticles is expected to enhance formulation flowability and facilitate powder delivery from nasal devices (Behl et al., 1998; Omer et al., 2018).

\subsection{X-Ray diffraction studies}

The physical behaviour and crystallinity of the spray-dried formulations were investigated using X-ray diffraction. X-ray diffraction spectra for drug, drug-free microparticles, drugloaded microparticles and a physical mixture of $\mathrm{RH}$ and sodium alginate are all shown in Figure 6. RH raw material showed sharp peaks at different angles, indicating crystallinity of the drug (Figure 6g). Crystal peak intensity decreased when the drug was spray-dried in polymeric formulations. The decrease in peak intensity (i.e. reduced crystallinity) was directly proportional to the ratio of polymer to drug. For example, the peaks were completely absent when polymer to $\mathrm{RH}$ ratio was as high as 90:10 (i.e. for A2 formulation) (Figure 6b), indicating that $\mathrm{RH}$ has converted to the amorphous form and was molecularly dispersed into the polymeric network, complying with previous research observations using other drug molecules and different excipients (Mahajan et al., 2012). On one hand, the amorphous form of a drug is known to have higher dissolution and possibly promoted bioavailability compared to its crystalline form (Remenar et al., 2003; Blandizzi et al., 2015). On the other hand, amorphous form is less stable and may have tendency to recrystallize during storage, causing changes in the physical properties of the formulation (Learoyd et al., 2008). Accordingly, the stability of RH-alginate microspheres (formulation A2) upon storage for two months was investigated at low $\left(5^{\circ} \mathrm{C} \pm 1\right)$ and room $\left(20^{\circ} \mathrm{C} \pm 2\right)$ temperatures. Experiments revealed that microsphere formulations had no marked changes in the X-ray spectra, regardless of the temperature used over the time course investigated (Figure 7). In the future, we will extrapolate our stability investigations to include higher temperatures and accelerated stability studies. 


\subsection{Thermogravimetric analysis (TGA)}

Moisture content studies using thermogravimetric analysis (TGA) can give information about the long term stability of drug and excipients (Ståhl et al., 2002). TGA revealed that residual water content was in the following order: $18.03 \pm 0.65(\%)$ for $\mathrm{A} 1>8.45 \pm 1.59(\%)$ for $\mathrm{A} 2>$ $7.53 \pm 0.54(\%)$ for $\mathrm{A} 3>5.43 \pm 0.15(\%)$ for $\mathrm{A} 4>4.54 \pm 0.69(\%)$ for A5 (Graph not shown), indicating the influence of polymer to drug ratio on residual moisture content of the spray dried formulations. Decreasing the polymer to drug ratio caused a decrease in the residual moisture content of the alginate microparticles $(p<0.05)$. Thus, sodium alginate can retain water within the particle matrix and reduce water evaporation during spray drying. Further studies are needed in the future to evaluate the long-term stability of our polymeric formulations at various temperatures.

\subsection{Differential Scanning Calorimetry (DSC)}

Differential scanning calorimetry (DSC) is commonly used to investigate possible interactions between blended materials. The thermal profiles of $\mathrm{RH}$ (raw material), drug-free microparticles, the physical mixture of sodium alginate and RH with different polymer to drug ratios $(90: 10,70: 30,50: 50$, and 30:70) and $\mathrm{RH}$ loaded sodium alginate microparticle formulations (A2, A3, A4 and A5) are all presented in figure 8. For the sodium alginate polymer, an endothermic peak was first detected at around $100^{\circ} \mathrm{C}$, which can be attributed to evaporation of residual water present within the polymeric network. This was followed by an exothermic peak at $239^{\circ} \mathrm{C}$, which is due to decomposition of the polymer. These findings agree with the TGA behaviour of this polymer reported previously by another investigator (Soares et al., 2004). However, the exothermic peak was absent when the polymer to drug ratio was low. The sharp endothermic peak observed for $\mathrm{RH}$ (raw material) at $248.57^{\circ} \mathrm{C}(\Delta \mathrm{H}$ $=117.35 \mathrm{~J} / \mathrm{g}$ ) represents its melting point, and indicates the high crystallinity of the drug, as also shown in other studies (Avachat et al., 2011). However, as the polymer ratio in the 
formulation is increased, the sharpness of the drug's endothermic peak is decreased with a forward shift of the onset temperature of the endotherm (from 212.58 to $224.88^{\circ} \mathrm{C}$ ) (Figure 8); this indicates partial loss of crystallinity of RH upon incorporation into the microspheres. The peak was absent in formulation A2, indicating that the drug existed in amorphous form and was uniformly distributed within the polymeric matrix (Pradhan et al., 2016).

\subsection{Drug release profile in vitro}

In vitro drug release study was performed in phosphate buffer solution ( $\mathrm{pH} 6.5)$ in an attempt to simulate the acidic environment of the human nasal mucosa. Figure 9 shows the cumulative release for formulations A2, A3, A4 and A5 at different time intervals. The time required for drug release to reach its maximum level (>95\%) was 60, 30, 10 and 1 min for A2, A3, A4 and A5 formulations, respectively. The rapid drug release is attributed to the high aqueous solubility of both drug and polymer and the small particle size of the microspheres. Polymer to drug ratio played a role in the drug release rate, so that decreasing the polymer concentration (e.g. when comparing A2 with A5) caused an increase in the drug release rate. Using low polymer concentrations caused the drug to diffuse through shorter channels within the polymeric network connecting the core to the surface of the microparticles. By contrast, when higher polymer concentrations are used, the network density of the polymeric matrix may increase, causing drug movement through longer channels to reach the particle's surface and be released. Rathananand and co-workers (2007) have investigated the release rate of levocetirizine from chitosan microparticles, and reported slower release rate upon increasing polymer concentration, agreeing with our findings. Rapid release of $\mathrm{RH}$ from alginate microparticles can possibly indicate absence of strong bonding between the drug and the polymer. Gavini and co-workers (2005) have reported a possible interaction between sodium alginate and metoclopramide hydrochloride, causing more prolonged release $(>3 \mathrm{~h})$. 


\subsection{Histopathological investigation of RH-loaded sodium alginate microparticles}

From our characterization studies, the most appropriate formulation seemed to be A2. Thus, the potential safety of this formulation for intranasal administration was further investigated using an isolated nasal sheep mucosa. Phosphate buffer solution ( $\mathrm{pH}$ 6.5) was used as the first negative control and the corresponding drug-free alginate microparticles was employed as a second negative control, whilst sodium deoxycholate $(1 \% \mathrm{w} / \mathrm{v})$ solution was used as positive control. The protocol of our histopathology experiments was adapted from an established study published three decades ago by Hermens and Merkus (1987).

Microscopic images of the microparticles (formulation A2) and drug-free microparticles did not show remarkable effects on the overall appearance of the animal's nasal mucosa (Figure $10 \mathrm{a}, \mathrm{b}$ ), which is contrary to the positive control (Figure 10c). Thus, the cilia lining mucosa and its components were apparently normal, and no necrosis was detected (Figure 10 a,b). As shown in Table 3, goblet cells, sero-mucinous glands and ciliated cells were intact, with detection of only slight focal sloughing of the cells. These findings agree with the observations of Kolsure and Rajkapoor (2012) who used nasal gels of zolmitriptan, and Patil and co-workers (2012) who used carvedilol-sodium alginate microspheres for intranasal administration. Microscopic results in this study suggested that optimized RH-loaded sodium alginate microsphere formulations had no apparent harmful effect on the nasal mucosa, and RH-loaded alginate microspheres are potentially safe and further in vivo animal experiments are needed in the future. To the best of our knowledge, this is the first study that reported the development of spray dried RH microspheres using the sodium alginate polymer. Further studies should take these formulations to the in vivo phase to demonstrate the advantages of nasal delivery of RH compared to oral administration. 


\section{Conclusions}

This study has demonstrated that spray drying is highly suitable for preparing RH-loaded sodium alginate microspheres. Inlet temperature had remarkable effect on morphology and yield of the spray-dried microparticles. Furthermore, formulation had an obvious effect on morphology, size and size distribution of the microparticles. Accordingly, alginate to drug ratio of 90:10 (w/w) was considered the best performing formulation. Additionally, X-ray diffraction studies revealed that the spray-dried microparticles prepared in this study were stable for at least two months. Importantly, the release rate of RH was significantly affected by polymer concentration in the formulation. The histopathological investigation showed that $\mathrm{RH}$ loaded sodium alginate was non-toxic to an isolated sheep mucosa. In-vivo studies using animal models are needed in the future to determine the amount of drug that may reach the brain, cerebrospinal fluid (CSF) and blood circulation after administration of RH-alginate microspheres in the forms of nasal powders.

\section{Conflict of interest}

Authors declare no conflict of interests

\section{Acknowledgements}

We thank the Ministry of Higher Education of Kurdistan Regional Government, Republic of Iraq, for funding this study. This is a collaborative study, and all authors have contributed significantly to conducting this research and writing this research article. 


\section{References}

Alhalaweh, A., Andersson, S., Velaga, S.P., 2009. Preparation of zolmitriptan-chitosan microparticles by spray drying for nasal delivery. Eur. J. Pharm. Sci. Off. J. Eur. Fed. Pharm. Sci. 38, 206-214.

Avachat, A.M., Bornare, P.N., Dash, R.R., 2011. Sustained release microspheres of ropinirole hydrochloride: effect of process parameters. Acta Pharm. Zagreb Croat. 61, 363-376.

Behl, C., Pimplaskar, H., Sileno, A., deMeireles, J., Romeo, V., 1998. Effects of physicochemical properties and other factors on systemic nasal drug delivery. Adv. Drug Deliv. Rev. 29, 89-116.

Blandizzi, C., Viscomi, G.C., Scarpignato, C., 2015. Impact of crystal polymorphism on the systemic bioavailability of rifaximin, an antibiotic acting locally in the gastrointestinal tract, in healthy volunteers. Drug Des. Devel. Ther. 9, 1-11.

Chaturvedi, M., Kumar, M., Pathak, K., 2011. A review on mucoadhesive polymer used in nasal drug delivery system. J. Adv. Pharm. Technol. Res. 2, 215-222.

Chegini, G., Taheri, M., 2013. Whey powder: Process technology and physical properties: A review. Middle-East J. Sci. Res. 13, 1377-1387.

Clogston, J.D., Patri, A.K., 2011. Zeta potential measurement. Methods Mol. Biol. Clifton NJ 697, 63-70.

Coppi, G., Iannuccelli, V., Leo, E., Bernabei, M.T., Cameroni, R., 2002. Protein immobilization in crosslinked alginate microparticles. J. Microencapsul. 19, 37-44.

DrugBank (Ed.), 2013. Ropinirole (DB00268). DrugBank.

Farid, R., Etman, M., Nada, A., Ebian, A.-E., 2012. Sodium alginate-based microspheres of salbutamol sulphate for nasal administration: Formulation and evaluation. Am J PharmTech Res 2, 289-307.

Gavini, E., Hegge, A.B., Rassu, G., Sanna, V., Testa, C., Pirisino, G., Karlsen, J., Giunchedi, P., 2006. Nasal administration of carbamazepine using chitosan microspheres: in vitro/in vivo studies. Int. J. Pharm. 307, 9-15.

Gavini, E., Rassu, G., Sanna, V., Cossu, M., Giunchedi, P., 2005. Mucoadhesive microspheres for nasal administration of an antiemetic drug, metoclopramide: invitro/ex-vivo studies. J. Pharm. Pharmacol. 57, 287-294.

Graessley, W.W., 1974. The Entanglement Concept in Polymer Rheology. Springer-Verlag, Berlin, Germany.

Hermens, W.A., Merkus, F.W., 1987. The influence of drugs on nasal ciliary movement. Pharm. Res. 4, 445-449.

Huh, Y., Cho, H.-J., Yoon, I.-S., Choi, M.-K., Kim, J.S., Oh, E., Chung, S.-J., Shim, C.-K., Kim, D.-D., 2010. Preparation and evaluation of spray-dried hyaluronic acid microspheres for intranasal delivery of fexofenadine hydrochloride. Eur. J. Pharm. Sci. Off. J. Eur. Fed. Pharm. Sci. 40, 9-15.

Illum, L., 2003. Nasal drug delivery--possibilities, problems and solutions. J. Control. Release Off. J. Control. Release Soc. 87, 187-198.

Ishikawa, F., Katsura, M., Tamai, I., Tsuji, A., 2001. Improved nasal bioavailability of elcatonin by insoluble powder formulation. Int. J. Pharm. 224, 105-114.

Jain, R.R., Mehta, M.R., Bannalikar, A.R., Menon, M.D., 2015. Alginate microparticles loaded with lipopolysaccharide subunit antigen for mucosal vaccination against Klebsiella pneumoniae. Biol. J. Int. Assoc. Biol. Stand. 43, 195-201.

Jiang, L., Gao, L., Wang, X., Tang, L., Ma, J., 2010. The application of mucoadhesive polymers in nasal drug delivery. Drug Dev. Ind. Pharm. 36, 323-336.

Khan, I., Yousaf, S., Subramanian, S., Korale, O., Alhnan, M.A., Ahmed, W., Taylor, K.M., Elhissi, A., 2015. Proliposome powders prepared using a slurry method for the generation of beclometasone dipropionate liposomes. Int. J. Pharm. 496, 342- 
350.Kharenko, E.A., Larionova, N.I., Demina, N.B., 2009. Mucoadhesive drug delivery systems (Review). Pharm. Chem. J. 43, 200-208.

Kolsure, P.K., Rajkapoor, B., 2012. Development of zolmitriptan gel for nasal administration. Asian J. Pharm. Clin. Res. 5, 88-94.

Kumar, T.P., Sirisha, B., Raju, P.N., Reddy, G.N., 2013. Nasal drug delivery: A potential route for brain targetting 2, 77-85.

Learoyd, T.P., Burrows, J.L., French, E., Seville, P.C., 2008. Modified release of beclometasone dipropionate from chitosan-based spray-dried respirable powders. Powder Technol. 187, 231-238.

Lee, M., Park, C.G., Huh, B.K., Kim, S.-N., Lee, S.H., Khalmuratova, R., Park, J.-W., Shin, H.-W., Choy, Y.B., 2017. Sinonasal Delivery of Resveratrol via Mucoadhesive Nanostructured Microparticles in a Nasal Polyp Mouse Model. Sci. Rep. 7, srep40249.

Mahajan, H.S., Tatiya, B.V., Nerkar, P.P., 2012. Ondansetron loaded pectin based microspheres for nasal administration: In vitro and in vivo studies. Powder Technol. $221,168-176$.

Mao, S., Chen, J., Wei, Z., Liu, H., Bi, D., 2004. Intranasal administration of melatonin starch microspheres. Int. J. Pharm. 272, 37-43.

Nidhi, Rashid, M., Kaur, V., Hallan, S.S., Sharma, S., Mishra, N., 2016. Microparticles as controlled drug delivery carrier for the treatment of ulcerative colitis: A brief review. Saudi Pharm. J. SPJ 24, 458-472.

Omer, H.K., Hussein, N.R., Ferraz, A., Najlah, M., Ahmed, W. Taylor, K.M.G., Elhissi, A.M.A., 2018. Spray-dried proliposome microparticles for high-performance aerosol delivery using a monodose powder inhaler. AAPS PharmSciTech, in press.Patel, C., Chaudhari, B., 2012. Study of Degradation Profile and Development of Stability Indicating Spectrophotometric Method for Ropinirole Hydrochloride under Acid/Base Hydrolytic and Oxidative Conditions. International Journals For Pharmaceutical Research Scholars 1, 27-.

Patil, S.B., Kaul, A., Babbar, A., Mathur, R., Mishra, A., Sawant, K.K., 2012. In vivo evaluation of alginate microspheres of carvedilol for nasal delivery. J. Biomed. Mater. Res. B Appl. Biomater. 100, 249-255.

Pradhan, R., Kim, S.Y., Yong, C.S., Kim, J.O., 2016. Preparation and characterization of spray-dried valsartan-loaded Eudragit ${ }^{\circledR}$ E PO solid dispersion microparticles. Asian J. Pharm. Sci. 11, 744-750.

Rassu, G., Soddu, E., Cossu, M., Brundu, A., Cerri, G., Marchetti, N., Ferraro, L., Regan, R.F., Giunchedi, P., Gavini, E., Dalpiaz, A., 2015. Solid microparticles based on chitosan or methyl- $\beta$-cyclodextrin: a first formulative approach to increase the noseto-brain transport of deferoxamine mesylate. J. Control. Release Off. J. Control. Release Soc. 201, 68-77.

Rathananand, M., Kumar, D., Shirwaikar, A., Kumar, R., Sampath Kumar, D., Prasad, R., 2007. Preparation of mucoadhesive microspheres for nasal delivery by spray drying. Indian J. Pharm. Sci. 69, 651.

Remenar, J.F., Morissette, S.L., Peterson, M.L., Moulton, B., MacPhee, J.M., Guzmán, H.R., Almarsson, O., 2003. Crystal engineering of novel cocrystals of a triazole drug with 1,4-dicarboxylic acids. J. Am. Chem. Soc. 125, 8456-8457.

Salade, L., Wauthoz, N., Vermeersch, M., Amighi, K., Goole, J., 2018. Chitosan-coated liposome dry-powder formulations loaded with ghrelin for nose-to-brain delivery. Eur. J. Pharm. Biopharm. 129, 257-266.

Seju, U., Kumar, A., Sawant, K.K., 2011. Development and evaluation of olanzapine-loaded PLGA nanoparticles for nose-to-brain delivery: In vitro and in vivo studies. Acta Biomater. 7, 4169-4176.

Soares, J.P., Santos, J.E., Chierice, G.O., Cavalheiro, E.T.G., 2004. Thermal behavior of alginic acid and its sodium salt. Eclética Quím. 29, 57-64. 
Ståhl, K., Claesson, M., Lilliehorn, P., Lindén, H., Bäckström, K., 2002. The effect of process variables on the degradation and physical properties of spray dried insulin intended for inhalation. Int. J. Pharm. 233, 227-237.

Szekalska, M., Amelian, A., Winnicka, K., 2015. Alginate microspheres obtained by the spray drying technique as mucoadhesive carriers of ranitidine. Acta Pharm. Zagreb Croat. $65,15-27$.

Taylor, L.S., Zografi, G., 1997. Spectroscopic characterization of interactions between PVP and indomethacin in amorphous molecular dispersions. Pharm. Res. 14, 1691-1698.

Tee, H., Chuah, L., Pin, Y., Rshih, A., A., Y., 2012. Optimization of spray drying process parameters of Piper betle L.(Sirih) leaves extract coated with maltodextrin. J. Chem. Pharm. Res. 4, 1833-1841.

Wen, M.M., 2011. Olfactory targeting through intranasal delivery of biopharmaceutical drugs to the brain - current development. Discov. Med. 11, 497-503.

Yeom, D.W., Chae, B.R., Son, H.Y., Kim, J.H., Chae, J.S., Song, S.H., Oh, D., Choi, Y.W., 2017. Enhanced oral bioavailability of valsartan using a polymer-based supersaturable self-microemulsifying drug delivery system. Int. J. Nanomedicine 12, 3533-3545. 


\section{Legend to Figures:}
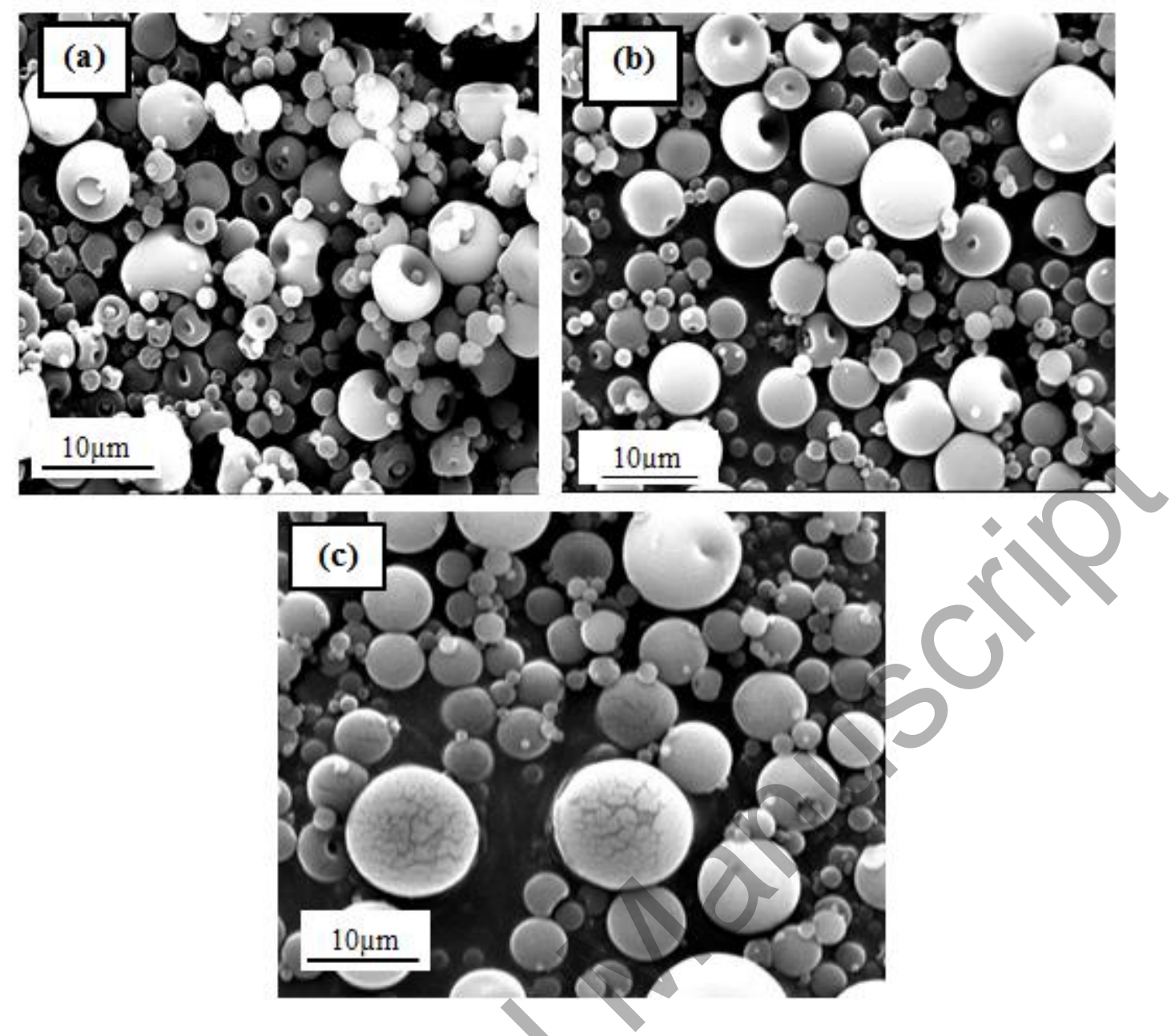

Figure 1: SEM images of sodium alginate microparticles at inlet air temperatures of (a) $160^{\circ} \mathrm{C}$, (b) $140^{\circ} \mathrm{C}$, and (c) $120^{\circ} \mathrm{C}$

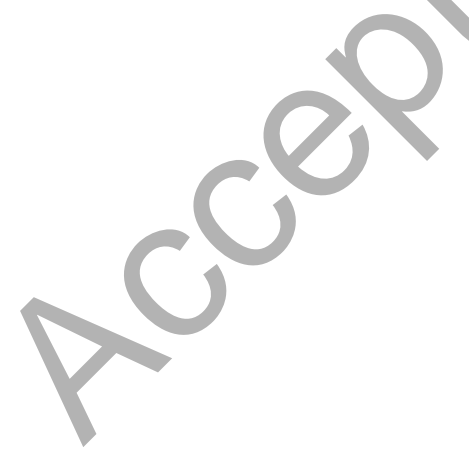




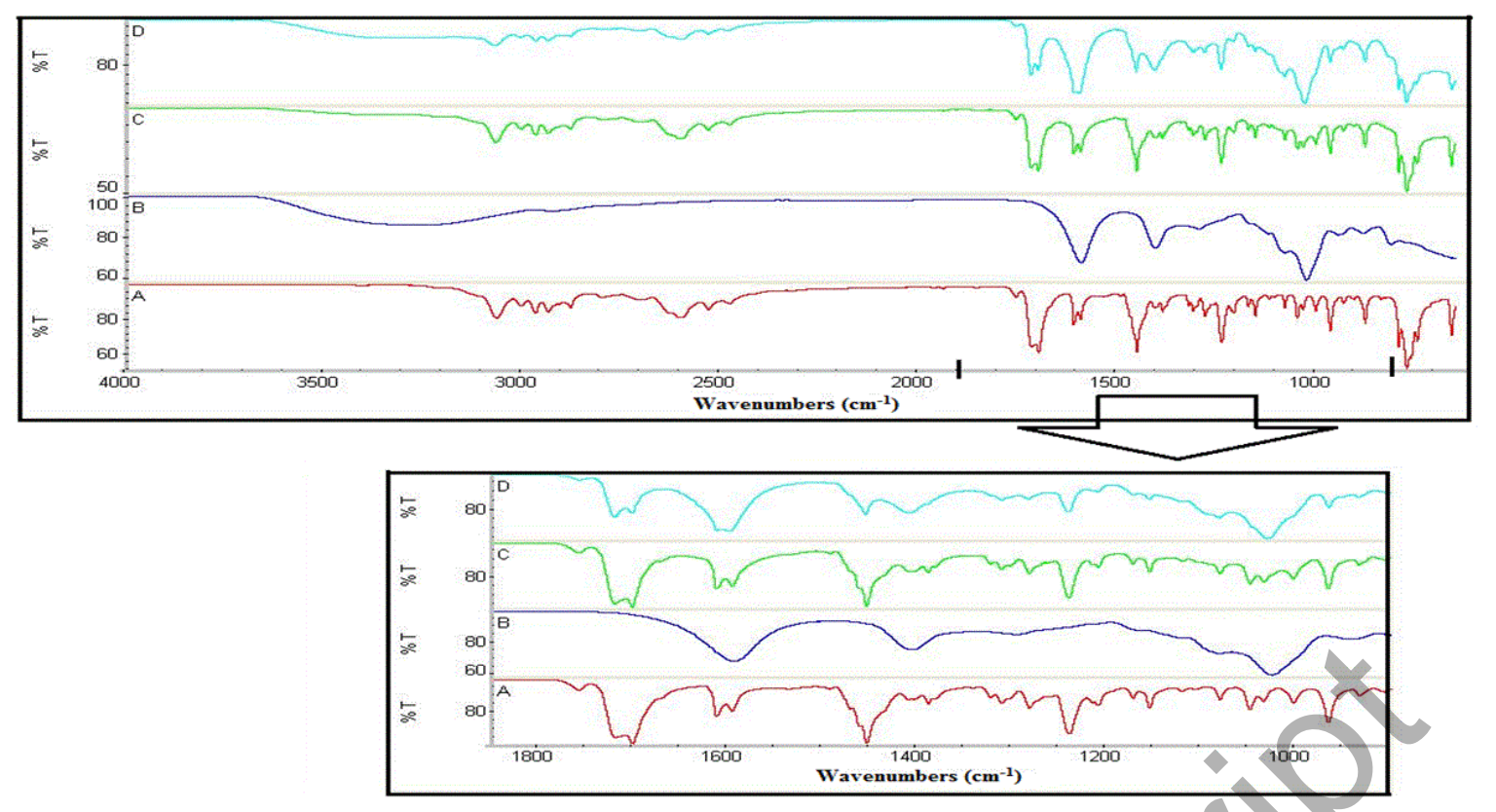

Figure 2: FTIR spectrum of (A) RH, (B) sodium alginate, (C) physical mixture of sodium alginate and RH $(1: 1 \mathrm{w} / \mathrm{w})$, and (D) spray dried $\mathrm{RH}$ loaded sodium alginate microparticles $(50: 50 \mathrm{w} / \mathrm{w})$. The lower graph magnifies the wave numbers area between 900 and $1900 \mathrm{~cm}^{-1}$ 


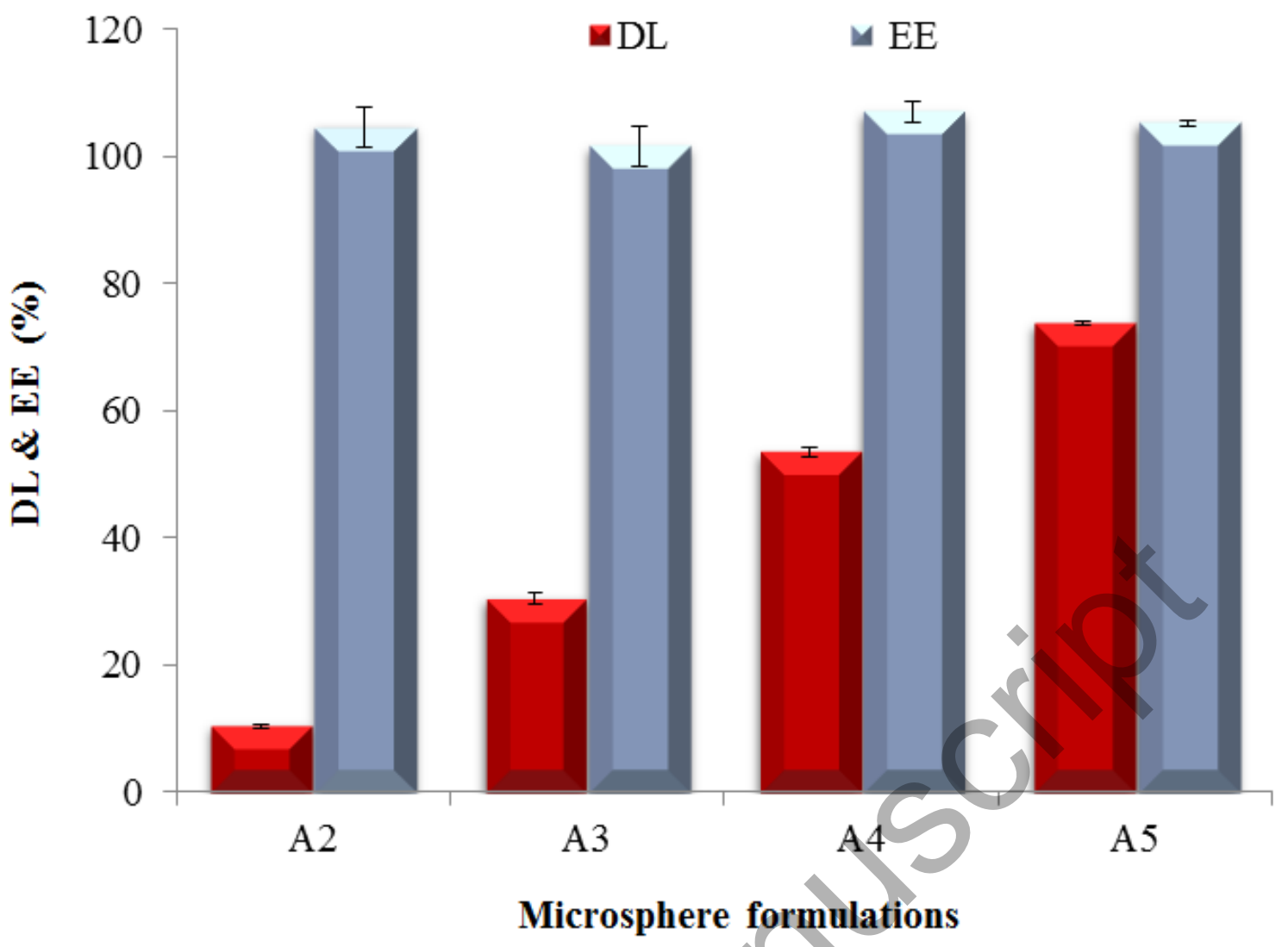

Figure 3: Drug loading (DL) and entrapment efficiency (EE) of spray-dried microspheres at various sodium alginate to drug ratios. Polymer to the drug ratios (w/w) were: A2 (90:10), A3 (70:30), A4 (50:50), and A5 (RH 30:70). (n=3 \pm SD) 


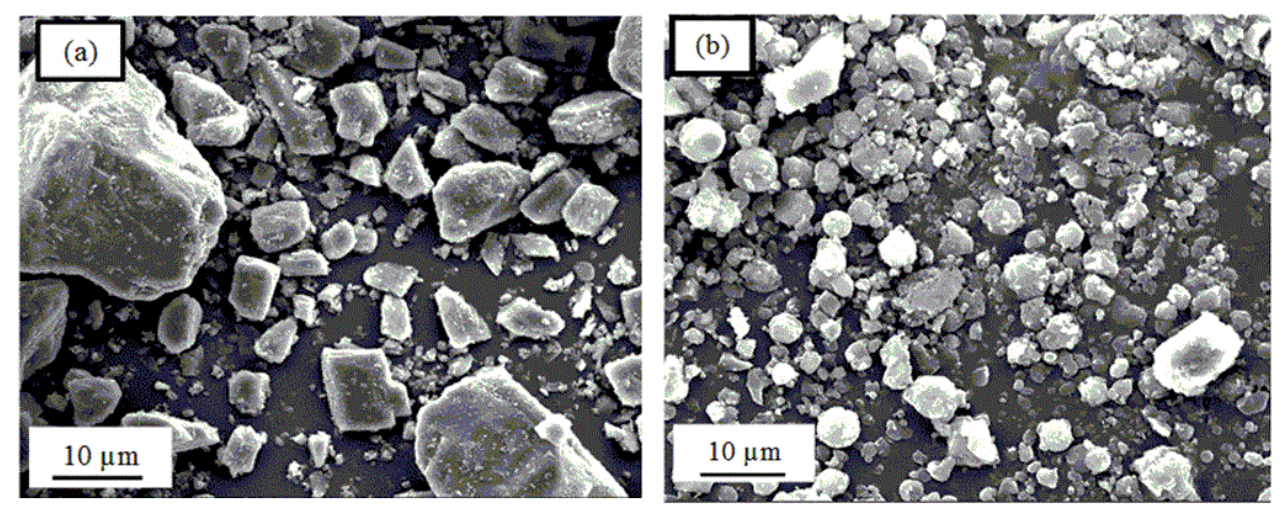

Figure 4: SEM images of RH (a) before spray drying and (b) after spray drying 

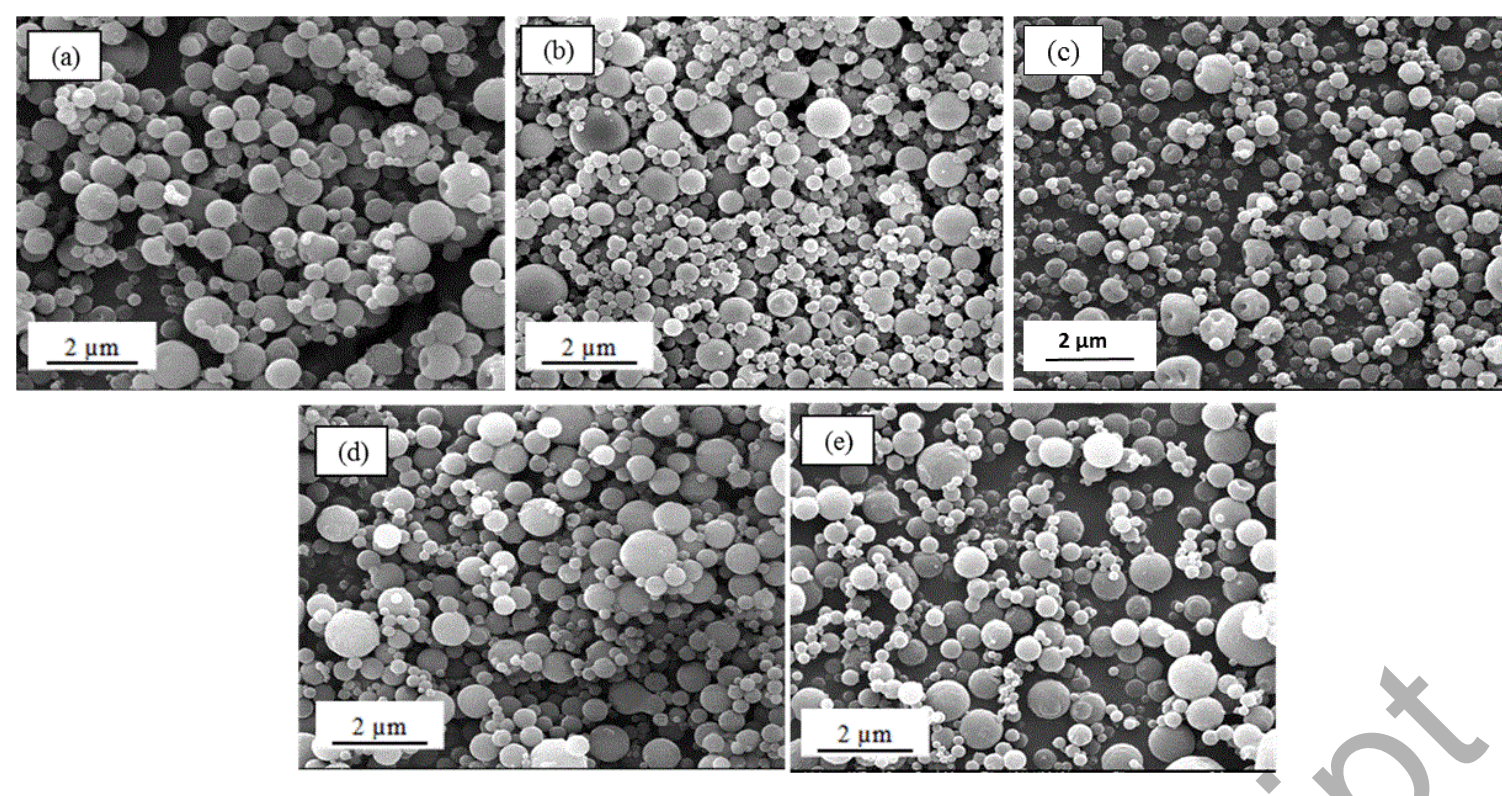

Figure 5: SEM images of (a) A1 (i.e. drug-free microspheres), (b) A2, (c) A3, (d) A4, and (e) A5 


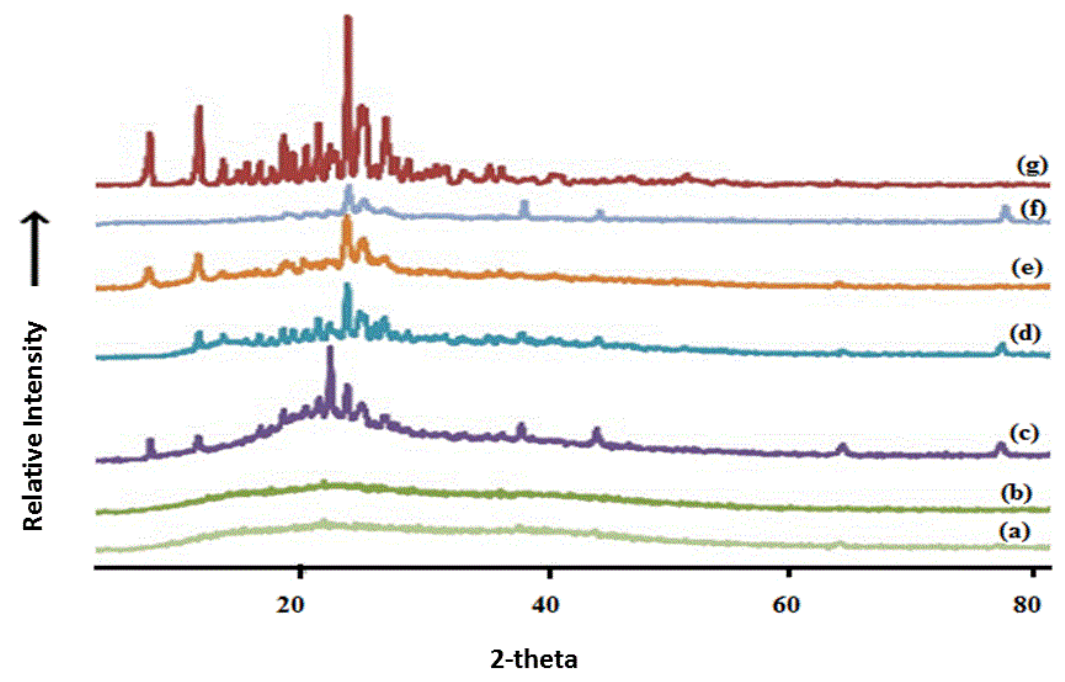

Figure 6: X-Ray diffractogram of (a) drug free microparticles, (b) A2, (c) A2 physical mixture, (d) A3, (e) A4, (f) A5, and (g) RH raw material 


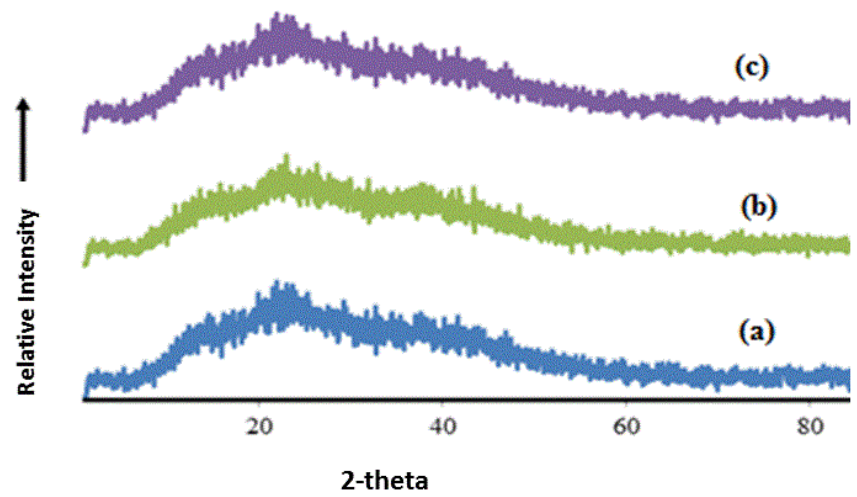

Figure 7: X-Ray diffractogram of (a) fresh A2 formulation, (b) A2 formulations stored at low temperature $\left(5^{\circ} \mathrm{C}\right)$ and $(\mathrm{c}) \mathrm{A} 2$ formulations stored at room temperature $\left(20^{\circ} \mathrm{C}\right)$ for two months 


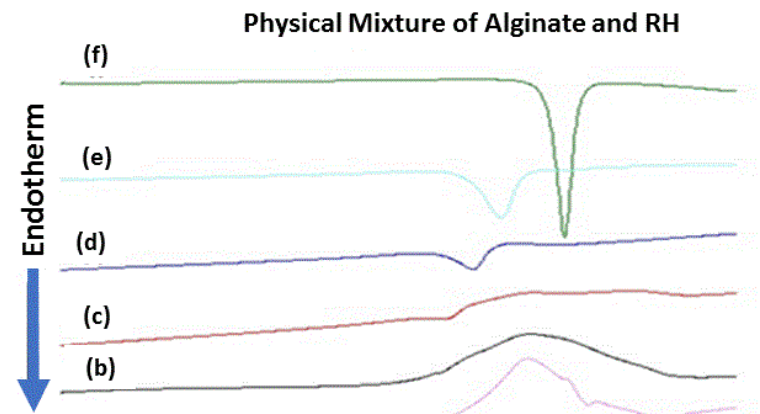

(a)

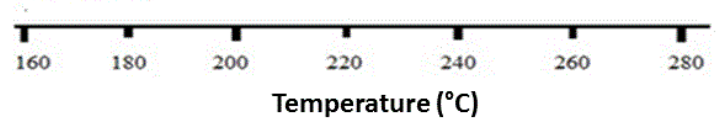

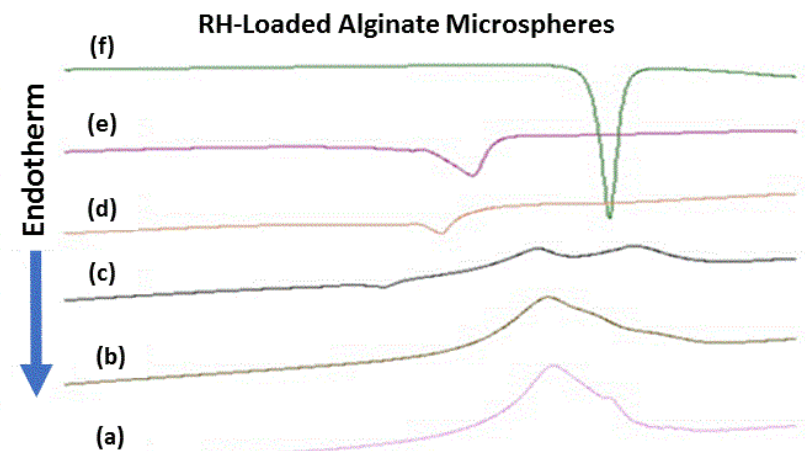

(a)

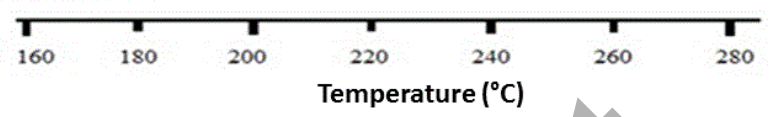

Figure 8: DSC thermograms of (a) drug-free microsphere, physical mixture of alginate-RH; (b) 90:10, (c) 70:30, (d) 50:50, (e) 30:70, RH loaded alginate microspheres; (b) A2, (c) A3, (d) A4, (e) A5 and (f) pure drug 


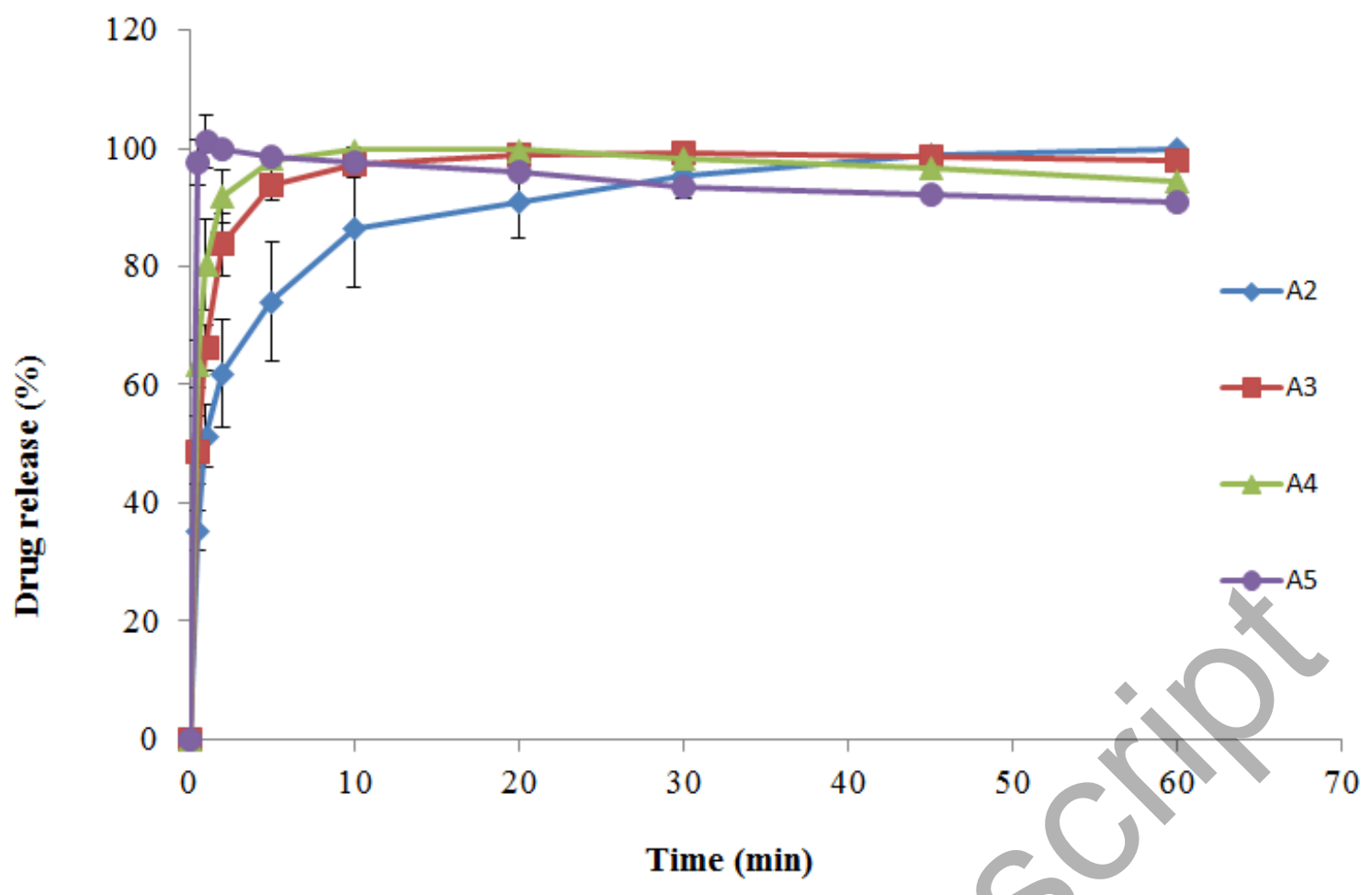

Figure 9: Release profile of various spray dried RH-loaded sodium alginate microsphere formulations carried out in phosphate buffer solution $(\mathrm{pH} 6.5)(\mathrm{n}=3 \pm \mathrm{SD})$ 

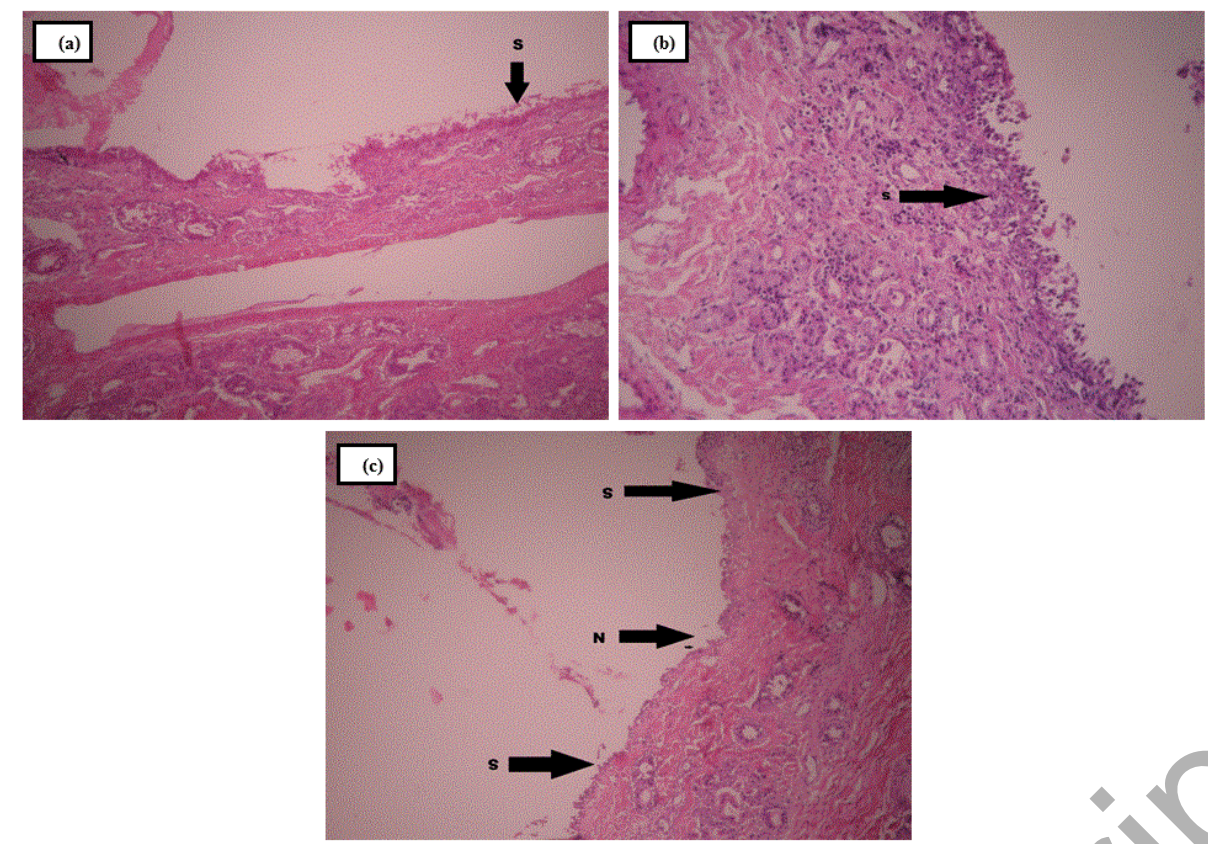

Figure 10: Microscopic images of sheep nasal mucosa treated with (a) A2 formulations, (b) drug free microparticles, and (c) positive control ( $10 \times 10$ magnification, $n=3)$. Sloughness is abbreviated as "S", necrosis is abbreviated as "N", and Inflammation is abbreviated as "I" 
Table 1: Sodium alginate microsphere formulations

\begin{tabular}{ccccc}
\hline $\begin{array}{c}\text { Formulation } \\
\text { code }\end{array}$ & $\begin{array}{c}\text { Ratio (w/w) } \\
\text { (polymer: RH) }\end{array}$ & $\begin{array}{c}\text { Sodium alginate } \\
(\mathbf{m g})\end{array}$ & $\begin{array}{c}\text { RH } \\
(\mathbf{m g})\end{array}$ & $\begin{array}{c}\text { Total weight } \\
(\mathbf{m g} / \\
\mathbf{1 0 0} \mathbf{~ m L})\end{array}$ \\
\hline A1 & $100: 0$ & 500 & 0 & 500 \\
A2 & $90: 10$ & 450 & 50 & 500 \\
A3 & $70: 30$ & 350 & 150 & 500 \\
A4 & $50: 50$ & 250 & 250 & 500 \\
A5 & $30: 70$ & 150 & 350 & 500 \\
\hline
\end{tabular}

Table 2: Particle size, size distribution, zeta potential and feed solution viscosity of alginate microparticle formulations using an inlet temperature of $140^{\circ} \mathrm{C}(\mathrm{n}=3 \pm \mathrm{SD})$

\begin{tabular}{cccccc}
\hline $\begin{array}{c}\text { Formulation } \\
\text { Code }\end{array}$ & $\begin{array}{c}\text { Viscosity } \\
(\mathbf{m P a} . \mathbf{)})\end{array}$ & $\begin{array}{c}\text { Product } \\
\text { yield }(\boldsymbol{\%})\end{array}$ & VMD $(\boldsymbol{\mu m})$ & $\begin{array}{c}\text { Span } \\
\text { Zeta Potential } \\
(\mathbf{m V})\end{array}$ \\
\hline A1 & $6.52 \pm 0.001$ & $70.27 \pm 1.26$ & $2.60 \pm 0.03$ & $2.71 \pm 0.01$ & $-70.07 \pm 0.73$ \\
A2 & $5.60 \pm 0.003$ & $69.50 \pm 0.68$ & $2.58 \pm 3.35$ & $1.72 \pm 0.06$ & $-62.57 \pm 0.21$ \\
A3 & $4.04 \pm 0.002$ & $69.70 \pm 1.03$ & $3.05 \pm 0.53$ & $1.52 \pm 0.03$ & $-56.93 \pm 3.73$ \\
A4 & $2.80 \pm 0.003$ & $69.37 \pm 1.58$ & $3.87 \pm 0.17$ & $2.11 \pm 0.04$ & $-46.35 \pm 1.23$ \\
A5 & $2.05 \pm 0.001$ & $68.07 \pm 1.12$ & $4.37 \pm 0.29$ & $4.13 \pm 1.19$ & $-39.82 \pm 2.38$ \\
\hline
\end{tabular}


Table 3: The comparative histopathological evaluation of nasal mucosa treated with a range of formulations and RH-loaded sodium alginate microparticles

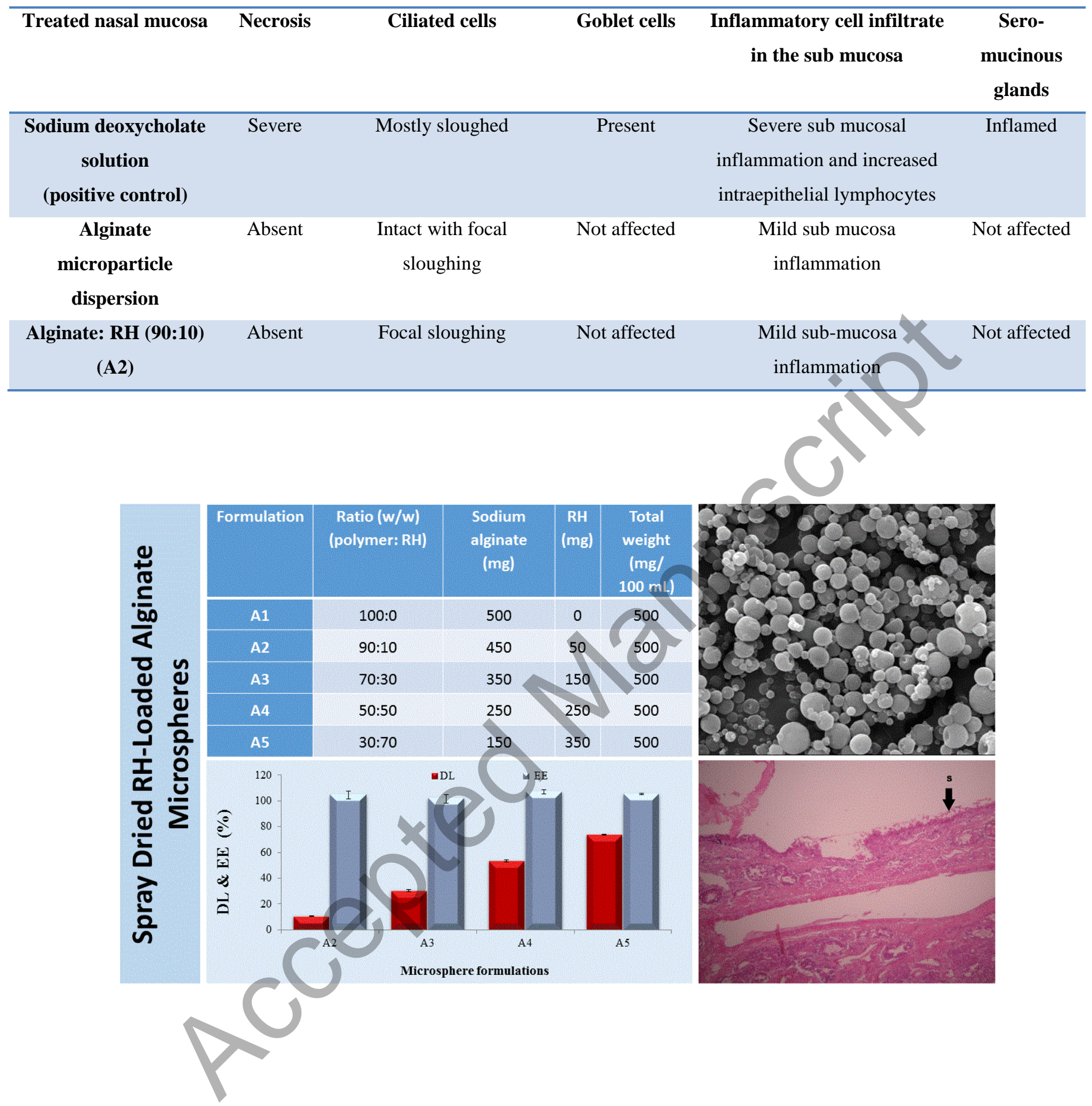

